Eastern Illinois University

The Keep

January 2005

\title{
The relationship between community diversity and exotic plants: cause or consequence of invasion?
}

\author{
Scott J. Meiners \\ Eastern Illinois University, sjmeiners@eiu.edu \\ Mary L. Cadenasso \\ University of California - Davis
}

Follow this and additional works at: https://thekeep.eiu.edu/bio_fac

Part of the Biology Commons, and the Plant Sciences Commons

\section{Recommended Citation}

Meiners, Scott J. and Cadenasso, Mary L., "The relationship between community diversity and exotic plants: cause or consequence of invasion?" (2005). Faculty Research \& Creative Activity. 120.

https://thekeep.eiu.edu/bio_fac/120

This Article is brought to you for free and open access by the Biological Sciences at The Keep. It has been accepted for inclusion in Faculty Research \& Creative Activity by an authorized administrator of The Keep. For more information, please contact tabruns@eiu.edu. 
The relationship between community diversity and exotic plants: cause or consequence of invasion?

\author{
Scott J. Meiners \& Mary L. Cadenasso
}

\title{
Introduction
}

Biological diversity is the modern unifying metric by which the health and status of communities and ecosystems are assessed throughout the world. Diversity is used to identify areas of special conservation concern while threats to biodiversity are the focus of remediation and legal action. Although the greatest threats to biodiversity are typically thought of as being the direct or indirect result of habitat loss and fragmentation, biological invasions follow closely behind. Despite this high priority position, our knowledge of the relationship between invasions and diversity remains relatively early in its development.

The invasion of terrestrial communities by exotic plant species is a major concern for ecologists and natural resource managers. With the increased speed of planned and unplanned movement of species throughout the world and greater rates of disturbance, exotic plants are becoming a larger component of regional floras [1-4]. Furthermore, exotic species already cover vast areas of many community types and sometimes dominate local plant communities. Invasions affect both natural and agricultural systems and cause financial, as well as biological problems in areas of heavy invasion. While there has been an increase in awareness of the problem of exotic invasive plant species, their community-level impacts remain relatively unknown [5-8]. A frequently observed pattern within plant communities is a negative relationship between diversity, typically expressed as species richness, and the cover of exotic plants (Fig. 1A). This simple pattern has been explained by two community-level mechanisms that differ in the cause/consequence relationship between diversity and invasion. In the first mechanism, diversity regulates the invasibility of the local plant community, causing the diversity/invasion relationship.

This view comes from theoretical and experimental community ecologists over the past several decades starting with Elton [9] and continues with empirical work (e.g., [10-12]). In the second mechanism, plant invasion results in the reduction of community diversity by driving other species from the local community. Changes in diversity in this context are a consequence of invasion. Conservationists largely present this view as justification for the control and regulation of exotic plant species $[13,14]$. 


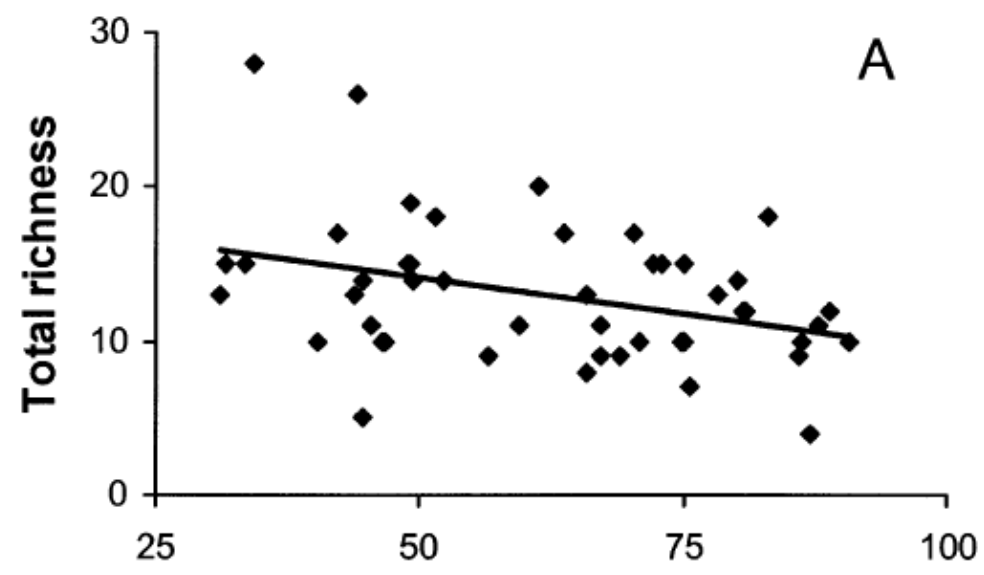

Exotic cover (\%)

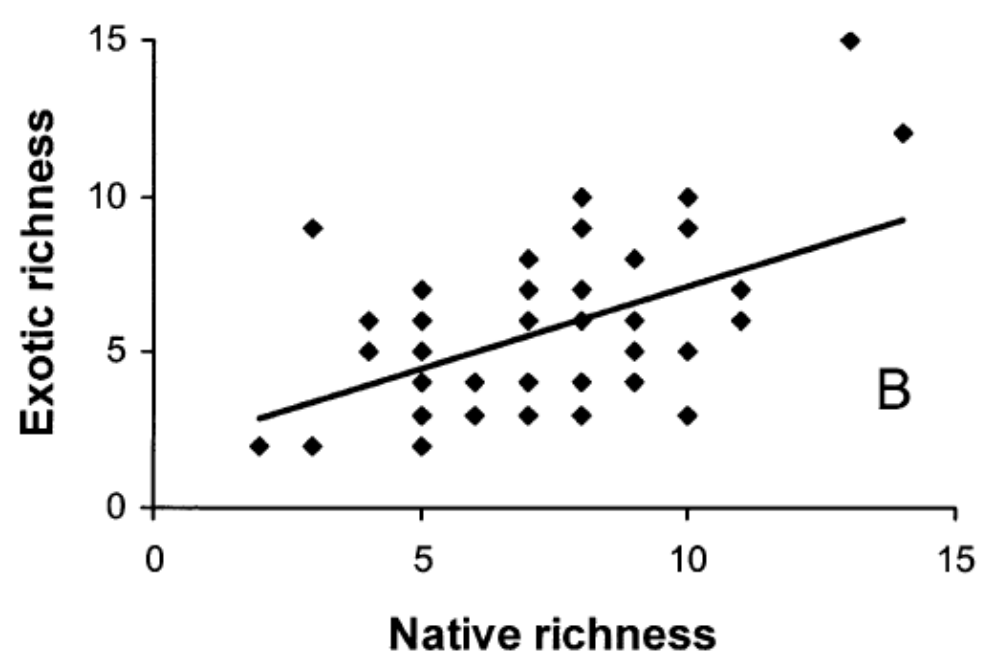

Figure 1. The relationship between invasion and species richness. (A) Total species richness as a function of the proportion exotic plant cover (Spearman rank-sum correlation $\mathrm{R}=-0.42$; $\mathrm{P}=0.003$ ) (B) Exotic species richness as a function of native species richness (Spearman rank-sum correlation $\mathrm{R}=0.40 ; \mathrm{P}=0.005$ ). Data were collected as percent cover in $1 \mathrm{~m} 2$ plots as part of the BSS.

Unfortunately, most studies have only addressed invasions from the cause or consequence perspective, leaving the true nature of the relationship unresolved. Currently, it is unknown whether the relationship between exotic plant invasion and diversity is caused by the local displacement of species by plant invaders, differential invasibilities of areas of varying diversity, or some combination of both. In this chapter, we specifically identify limitations of the current perspective on invasion and propose a conceptual framework from which to address the nature of the relationship between diversity and invasion. The framework aims to abstract the components of this relationship to allow generalization across systems and invaders, thereby enhancing ecological understanding of the causes and consequences of invasion. Several case studies are provided to illustrate 
the necessity of separating these two disparate perspectives of plant invasions.

\section{Scale and the invasion of plant communities}

Before directly addressing the relationship between diversity and invasion, it is first necessary to deal with the issue of scale. A hierarchical perspective of biological invasions reveals three nested scales which interact to determine invasions and their impacts in communities [15]. The coarsest scale, the regional scale, determines the species pool of invaders and residents, setting the potential range of species interactions. The intermediate scale, that of the landscape, determines which species within that larger regional pool will be able to colonize a given habitat based on their presence within the landscape, their vagility and physiological tolerances. The finest scale of interest is that of the neighborhood; the scale at which species interacts. Interactions lead to differential performance of the species, resulting in the realized composition of the neighborhood. At this fine scale, individuals may interact to influence invasion success or to generate the impacts of an invasion. Therefore, the most appropriate scale for studying the diversity/invasion relationship should match the scale at which organisms interact within a system.

The scale of interaction varies widely with the type of system being studied and with the specific interaction involved. Within experimental microcosms or modeling studies of community invasibility, all species within the community interact, or at least have the potential to interact $[16,17]$. This is in marked contrast to the condition in terrestrial plant communities, where interactions occur at neighborhood scales $[18,19]$. Typically, only plants with canopy or root overlap have the potential to interact. For example, two herbaceous plant species may compete strongly when in close proximity, but would have no effect on each other when separated by even a few meters. For this reason, the total number of plant species in an entire community should have no bearing on the overall invasibility of that community. Rather, fine-scale, within-community patterns of diversity may determine neighborhood invasibility. What constitutes a neighborhood in a particular system should parallel the scale at which organisms interact, probably from $10 \mathrm{~cm} 2$ or less for small plants and emerging seedlings to $50 \mathrm{~m} 2$ or more for large canopy trees.

Plants in terrestrial ecosystems are immobile and compete locally for largely immobile resources such as light and soil nutrients. This leads to the development of heterogeneity in local competitive environments, even within sites heavily invaded by an aggressive exotic species. This interaction heterogeneity explains why plant invasions rarely, if ever, directly lead to the loss of a species from an entire community. Species may be lost from areas directly impacted by an invasion, but will persist in spatial refugia not dominated by the invader (e.g., [20-22]).

While competitive interactions dominate the ecological literature on invasions 
[23], there are several other direct and indirect mechanisms through which plant invaders could interact with the resident community. These include allelopathic interactions [24-26], associational defenses [27], influences on nutrient dynamics $[28,29]$ and alterations of soil biotas [30]. Similar to competitive interactions, all of these interactions function at relatively fine scales.

Scale emerges as a critical variable when assessing apparent conflicting relationships of diversity and invasion published in the literature. At regional scales, the relationship between exotic and native species richness is often a positive one [4,31-34], while at fine scales within sites, the same communities may show a negative correlation between exotics plants and native species richness [32, 33, 35]. Diversity at regional scales is less determined by species interactions and more the result of changes in abiotic factors such as disturbance rate or productivity $[36,37]$ or variation in historical, evolutionary and biogeographical influences [38]. Native and exotic species appear to respond to this regional variation in abiotic conditions in a similar manner $[4,19,34$, $39,40]$, resulting in the positive spatial associations at coarser scales. Overall, community-level controls on invasion must function through local processes of interaction with the resident community. Likewise, the majority of impacts on the community would be expected to be manifested at fine scales that match the scale of species interactions. These local dynamics are nested within the regional context that determines the pool of native and exotic species and the availability of species to colonize a particular site (i.e., propagule pressure). Throughout the remainder of this paper, we will focus only on finescale causes and consequences of plant invasion.

\section{Cause: diversity and the regulation of community invisibility}

Interactions between invading species, the existing plant community and microhabitat conditions influence the ability of an exotic plant species to invade a site. Within plant communities, areas with lower diversity are often thought to be more susceptible to invasion than relatively species-rich areas [9, $39,41-44]$. This is because species-poor microsites may have more available resources, or vacant niches, allowing a specific exotic plant species to become established $[9,10,45]$. Experimental evidence suggests that higher diversity areas use resources more completely, leaving few colonizable niches [10,12, $19,45]$. Local resource availability has been found to be critical in determining neighborhood invasibility in many studies [12, 46-49], and may represent a general explanation for fine-scale invasibility patterns $[48,50]$. Alternatively, it may not be the diversity, but the composition of the neighborhood that regulates invasibility $[11,22,51,52]$. Higher diversity areas would be more likely to contain competitively dominant species through sampling from a limited species pool $[10,11,53]$ and are thus more likely to resist invasion. This is commonly referred to as an ecological sampling effect [53]. 
The diversity-invasibility hypothesis has been tested in herbaceous communities with contrasting results. Neighborhoods of higher diversity were more resistant to invasion in some studies $[10-12,19,52]$ while other studies found higher diversity plots to have equal or greater invasibilities [4, 32, 33, 51, 54-56]. Positive associations between diversity and invasion suggest that the same basic factors which make a microsite able to support many native species also make them able to support a diverse group of exotic species [4].

The quantity of evidence currently available on the diversity-invasibility hypothesis shows that diversity can regulate neighborhood invasibility in some systems, but that the directionality of this relationship appears to vary. The more important research themes now become the determination of the conditions under which diversity regulates community invasibility and the development of conceptual models that explain the variation in the direction of this relationship. Neighborhood diversity appears to limit the establishment of invading plant species in communities dominated by equilibrium dynamics, particularly in those communities strongly structured by competitive interactions such as in the nutrient limited sites studied by Tilman and colleagues [10, $45,57-59]$. Sites dominated by non-equilibrial dynamics, such as successional sites or those with otherwise high species turnover, appear to have a positive association between invasion and fine-scale diversity [19, 32, 35, 55]. However, this dichotomy may be artificial, as invasibility has been predicted to respond unimodally along diversity gradients when both facilitative and competitive interactions structure the community $[23,55]$. The directional responses seen in many systems may therefore represent the extremes of the gradient, or situations where either positive or negative interactions dominate.

The variation in the diversity-invasibility relationship across systems may also reflect the short-term nature of the majority of studies. Our ability to make reliable predictions about ecological systems is often limited by the temporal extent of available data [60]. The lack of predictive models in invasion biology may therefore be linked with the lack of sufficient long-term data.

\section{Consequence: invasion impacts on diversity}

While exotic plant invasions alter plant community composition and structure, the direct effects on diversity patterns are largely unquantified. Unfortunately, the vast majority of studies are observational, with little ability to assess the direct impacts of plant invasion on diversity [8]. It appears that exotic plant invasions are associated with a decrease in the number of species in natural communities [6,61-64]. However, this pattern is clearly not ubiquitous across all plant communities [65-68].

Differences among studies in the measure of invasion complicate attempts at generalization. Studies that relate richness of exotics to native diversity often find a positive correlation [66] while studies that assess invasion by cover 
or dominance tend to find negative associations $[61,69,70]$. Within a single community, it is possible to have both a positive association between native and exotic species richness and a negative association between total richness and exotic plant cover (Figs $1 \mathrm{~A}$ and $1 \mathrm{~B}$ ).

Negative associations between exotic plant cover and community diversity have been used to suggest that invading exotic species do not merely fill vacant niches in natural communities [10], or replace native species one-for-one, but that they displace species disproportionately from the community, lowering diversity. Field studies of invasive exotic plants often cite this hypothesis, either as a correlation or as anecdotal information. However, this direct interaction has rarely been experimentally tested.

The competitive displacement of native plant species is often used as justification for the eradication of individual exotic species, although the perceived relationship with diversity may not exist $[13,67,68,71]$. Many, if not most exotic species have only trivial impacts on community structure, becoming minor components of the plant community that increase regional species diversity $[5,72]$. Problematic exotic species, those which become widespread and locally dominant, are generally found to be competitively superior to native species in two-species competition experiments [73-75]. However, it is not known whether exotic species are, on average, competitively superior to native plant species, which would be necessary to result in lowered diversity across a community. Increases in richness or species performance following invasive species removal suggest that competitive displacement may result from some invasions [76-83].

An excellent example of exotic plant invasion impacts is that of Lonicera maackii. This species, a bird-dispersed shrub native to Asia, has become widespread throughout the eastern United States [84]. It has become a problematic invader of deciduous forests, particularly second growth and disturbed forests [85-87] and often dominates the forest understory in heavily invaded sites. Observational data show that this invader is associated with declines in tree seedling abundance and in the abundance and diversity of the herbaceous understory $[63,83,87]$. The mechanisms behind this association have been tested experimentally, showing that L. maackii directly reduces the growth and fecundity of herbaceous annual and perennial understory plants $[77,78,83]$ and competes with tree seedlings [88, 89]. Indirect impacts of L. maackii include protection of tree seedlings from deer browse [88] and increased tree seed predation by rodents (S. J. Meiners, unpublished data). Taken together, this suite of studies documents both patterns indicative of invasion impacts and documents direct and indirect interactions that generate these patterns. This is one of the few species invasions whose community-level impacts have been characterized mechanistically. However, beyond this species' connection to relatively open forest stands and gaps [85, 87], community-level controls on invasion success are unknown. 


\section{Cause versus consequence: invasibility versus impacts}

Clearly, the mechanism(s) that result in the often-observed relationships between exotic plant invasion and community diversity are unclear in current ecological literature. Associations between diversity and exotic plant cover have been used as evidence for both the regulation of neighborhood invasibility by diversity and the impacts of exotic plants on resident species. These two pathways of interaction must be separated conceptually to assess the relationship between exotic plant invasion and community diversity. These contrasting mechanisms can be formalized into two hypotheses, the invasibility hypothesis and the impact hypothesis (Fig. 2). The hypotheses differ in the role of diversity - as a regulator of exotic plant invasion or as a response to invasion. These two mechanisms also function at significantly different ecological stages, one at the establishment phase of the invader, the other once an invasion has successfully occurred and the species begins to spread within a site. In the invasibility hypothesis, the diversity of the neighborhood serves as an ecological filter that determines the invasion success of an exotic species. While there is no a priori reason to expect a single direction for the outcome of this interaction, most studies have focused on the inhibition of invasion by diversity. This reflects the overwhelming focus on competitive or other negative interactions in the exotic species literature [23]. Under this hypothesis, early seedling establishment and performance of the exotic species would be expected to vary with neighborhood diversity.

\section{Invasibility Hypothesis}
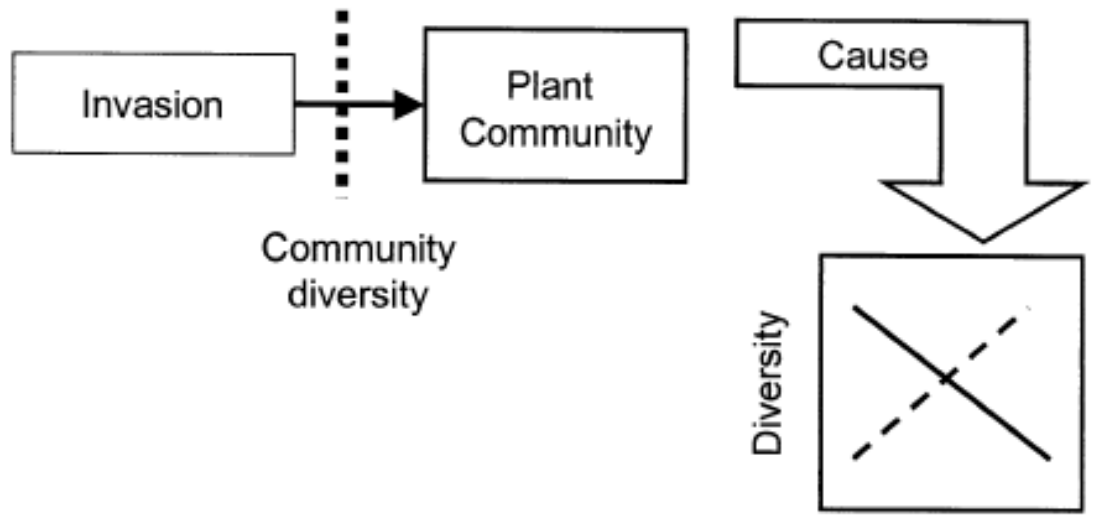

Impacts Hypothesis

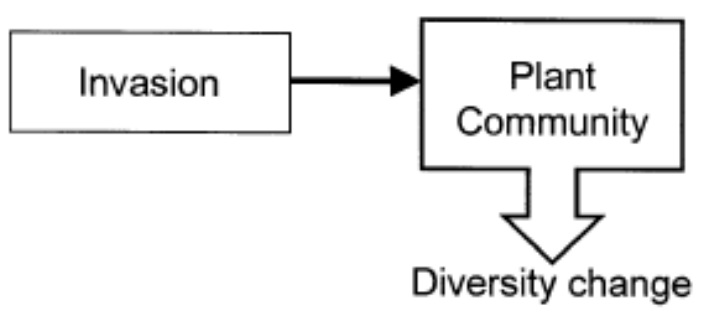

Consequence 
Figure 2. Schematic model of the two major hypotheses explaining the relationship between community diversity and exotic plant invasion. The invasibility hypothesis states that community diversity regulates the invasion of exotic species into a community, generating a relationship between diversity and exotic plant invasion. The impact hypothesis states that following invasion by exotic species, interaction between the resident community and the invader lead to changes in community diversity. As there is no a priori assumption of directionality for this relationship, both positive and negative diversity/invasion relationships are shown.

In the impact hypothesis, exotic species invade a neighborhood and subsequently interact with species residing within the community, resulting in altered diversity. This is typically thought to occur via the invader competitively displacing species currently in the area $[8,64,77]$, or by preventing the establishment of other species [11,22]. Species displacement would result in a reduction in neighborhood diversity if individual exotic species, on average, displaced more than one resident species. While positive interactions between invaders and other species have rarely been documented, the invasion of a species that facilitates the growth or establishment of other species may directly increase neighborhood species richness.

Both invasibility and impacts processes may generate similar changes in neighborhood diversity in association with exotic plant species, but would differ mechanistically. The diversity/invasion relationship of different exotic species may be explained by different mechanisms, or both may simultaneously operate to determine the relationship of an invader to community structure. The diversity/invasion pattern exhibited by the plant community will be the net effect of these two independent processes. It is also possible that species that exhibit no associations with neighborhood diversity may actually have counteracting invasibility and impact relationships.

Finally, as null a hypothesis, there may be no mechanistic relationship between exotic species and diversity. Diversity and invasion may both respond to similar extrinsic factors that generate associations without direct interaction. For example, microsite conditions that generate spatial patterning in diversity may also favor the establishment of an exotic plant species. However, this would probably lead to fine-scale variation in dominance of individual exotic species with variation in microsite conditions. Since many exotic species tend to be problematic across many community types and at regional scales, this alternative seems unlikely. Variation in local seed input may also generate positive associations between exotic and native species, even when higher diversity results in lower invasibility [19]. Because most plant communities are seed-limited $[10,90,91]$, and exotic plant species tend to be extremely vagile $[44,92,93]$, exotic species may be the first plants to invade a disturbed area, resulting in low diversity with high invasion. In this situation, the relationship between invasion and diversity would disappear as the less vagile native species invade [94]. 
The variation in the direction and strength of the relationship between exotic plant invasion and diversity in the ecological literature may partly result from the lack of a useful conceptual framework that separates out the invasion process from subsequent species interactions. Most observational and experimental studies artificially integrate both mechanisms into a single assessment of invasion, therefore obscuring the species interactions underlying the community dynamics associated with the invasion.

\section{Case-studies: Lonicera japonica and Rosa multiflora}

The limited temporal duration of most studies constrains our understanding of the causes and consequences of exotic plant invasions [5, 8, 66, 95-97]. While most plant invasions occur over time periods of decades or longer, most experimental studies of invasions are brief, lasting only 1-2 years. Similarly, observational sampling studies frequently only capture a single snapshot of community associations, yielding little information on how these associations developed. Even studies that have incorporated time spans matching the scale of invasions frequently have only a few sample periods, typically only before and after invasion [65, 97-99] and do not capture the complex dynamics during the intervening period.

To explore the utility of our conceptual framework for understanding the community dynamics that shape the relationship between exotic species and diversity, we use long-term data of species invasions in abandoned agricultural land from the Buell-Small Succession Study (BSS). This study has recorded the presence and percent cover of all species occurring within permanent plots in 10 abandoned agricultural fields since 1958 [100]. The fields vary in crop prior to abandonment (hay versus row crops) and in the year of abandonment (1958-1966). Each field contains 48, $0.5 \times 2.0 \mathrm{~m}$ plots that were sampled annually from 1958-1976 and in alternate years since 1976 . This longterm data has provided a unique opportunity to study the function of exotic plant species within dynamic communities [22, 72, 94]. Individual plots can be followed over the course of an invasion to simultaneously determine the factors that regulate community invasibility and the community impacts of the invasion [72].

The two most common and abundant exotic species within the study are Lonicera japonica and Rosa multiflora. We use these two species to examine patterns of invasion and impacts on species richness over the course of the invasions. Both of these species are problematic at a regional scale and are typical of the plant species that are the focus of diversity/invasion studies in that they are widely believed to be detrimental to native ecosystems [14]. Lonicera japonica is a bird-dispersed liana that is native to Asia and has become widespread throughout the eastern United States [101]. This species has been shown to compete strongly with native tree species [74]. Rosa multiflora, a 
bird-dispersed shrub, also native to Asia, was purposefully introduced as a living fence and as erosion control [102].

We analyzed data from years 5-15 and 10-20 post-abandonment for $\mathrm{L}$. japonica and R. multiflora, respectively. These periods represent the beginning and midpoint of the species invasions within the study (Fig. 3). We documented three basic patterns for each species to assess the relationship between invasion and diversity: 1) the relationship between invader cover and species richness as a general pattern at a single point in time, 2) the relationship between species richness and invasibility, and 3) the relationship between invasion and subsequent species loss.

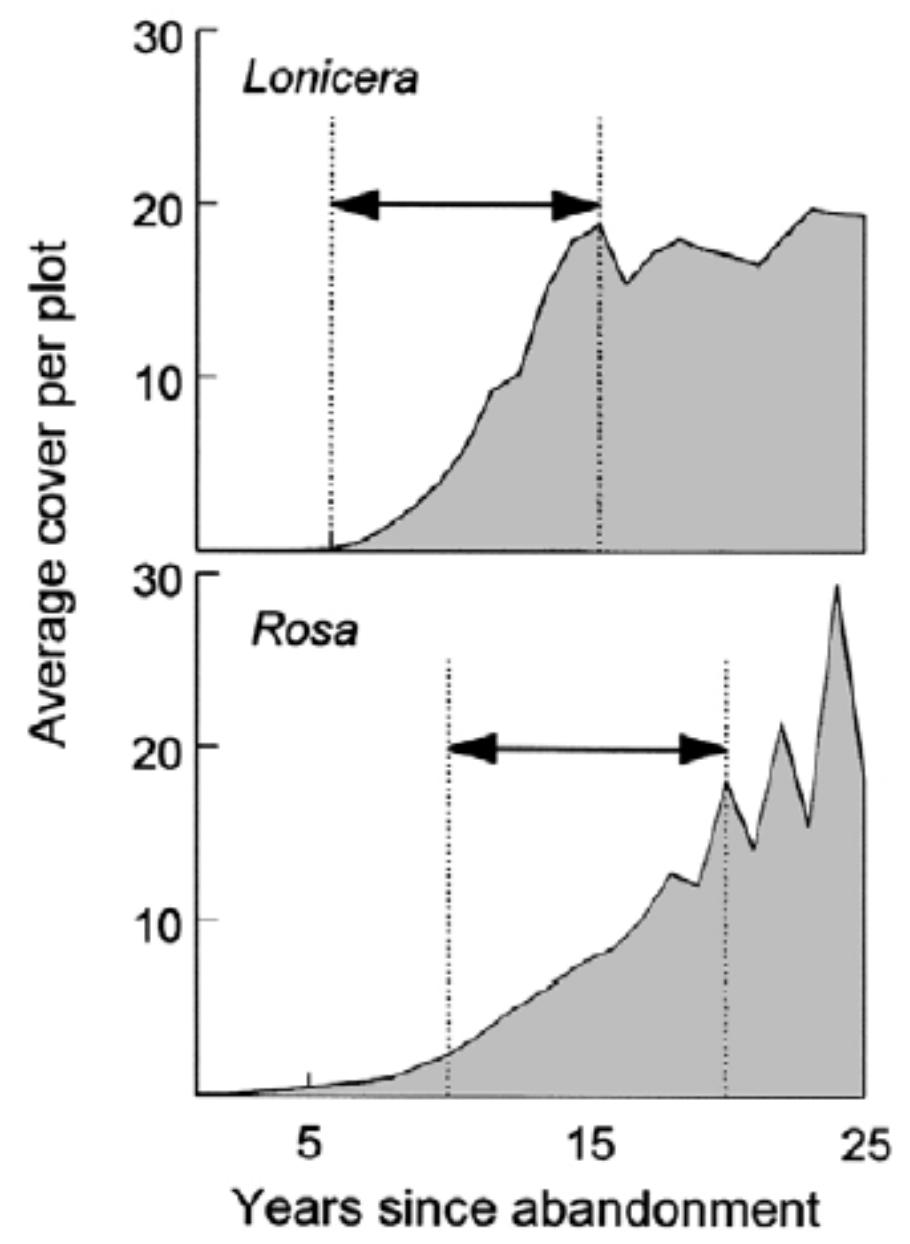

Figure 3. Temporal patterns of cover for Lonicera japonica and Rosa multiflora during succession within the BSS data. Arrows indicate the time span over which community dynamics in association with each invasion were assessed.

We determined the associations between total species richness and R. multiflora and L. japonica cover within plots at the midpoint of each invasion. This analysis is analogous to the one-time community sampling studies frequently 
conducted to assess the impacts of exotic plant invasion. For both species, there was a significant, negative relationship between the cover of the invading species and the total species richness of each plot (Fig. 4). This relationship by itself does not elucidate any mechanisms that generate the observed pattern, but suggests interaction between the community and the invader.

For all plots that were uninvaded at the beginning of the observation period, we determined the relationship between initial species richness and the probability of subsequent invasion during the observation period for each species.

This determines whether the invasibility of plots changes with species richness. For both species, plots with higher initial species richness were more likely to become invaded over the observation period than were plots with lower species richness (Fig. 5). The dynamics demonstrated by these species are in the opposite direction of most theoretical and experimental results, which show negative associations between invasibility and diversity. The selective invasion of high richness plots by these two species would tend to generate a positive association between invasion and diversity. Patterns of diversity are transient within the BSS, suggesting that there are no inherent differences between high and low richness plots that may influence invasibility. Invasibility at the neighborhood scale appears to be influenced primarily by stochastic events that generate opportunities for establishment [103], neighborhood species richness, and positive and negative interactions with resident species [55]. Once invasion had occurred, initial species richness did not influence the increase in cover of either species.

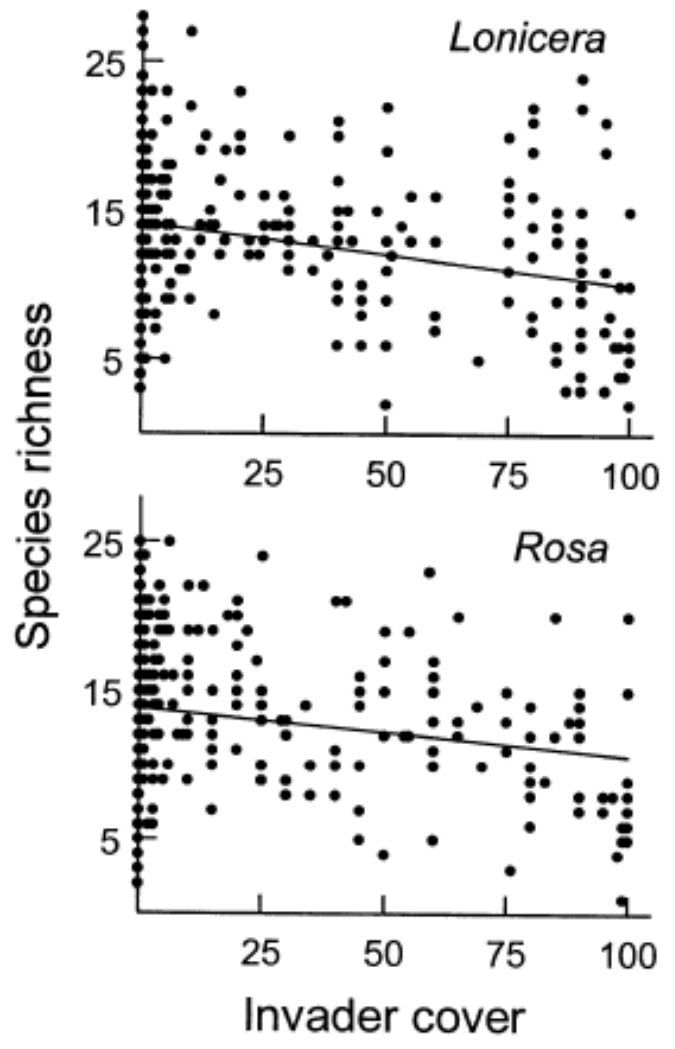


Figure 4. General association between invader cover and species richness for Lonicera japonica and Rosa multiflora. Regression analysis: Lonicera - F1,478 = 40.84; $\mathrm{P}=0.0001 ; \mathrm{R} 2=0.08 ;$ Rosa $-\mathrm{F} 1,478=16.86 ; \mathrm{P}=0.0001 ; \mathrm{R} 2=0.03$.

Finally, we determined the association between the increase in cover of the invading species and the change in species richness for those plots that were invaded during the observation periods. Change in cover for these two invaders represents increased cover of established individuals and, to a lesser extent, the recruitment of new individuals. This analysis assesses the ability of the invading plant to influence other species within the neighborhood [72]. As the cover of both invaders increased, the change in total species richness of the plot changed from a slight increase in richness over time to a net loss of species (Fig. 6). This shows that species were disproportionately lost from plots that were heavily invaded, strongly suggesting that both invaders were displacing resident species.

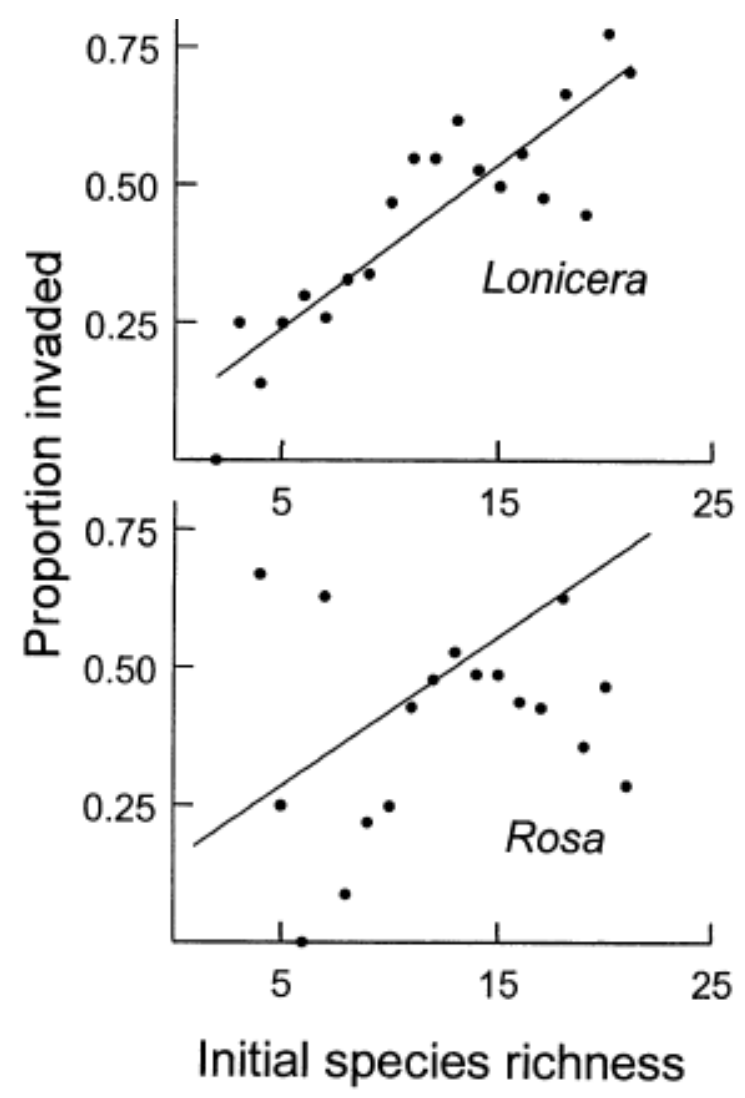

Figure 5. Influence of initial species richness on plot invasibility for Lonicera japonica and Rosa multiflora. Line represents logistic model predictions, points represent actual proportion of plots invaded where $\mathrm{N}=3$. Logistic regression analysis: Lonicera $-\chi 2=7.51, \mathrm{df}=1 ; \mathrm{P}<0.01 ;$ Rosa $-\chi 2=4.62, \mathrm{df}=1 ; \mathrm{P}<0.05$

Both invasibility and impact processes interact to generate community structure and dynamics associated with the invasion of these two species. The 
overall negative association seen in the single-sample data is the net combination of both of these factors. Interestingly, these two processes are antagonistic to each other, as selective invasibility would generate a positive association while invader impacts would generate a negative association. Invader impacts are clearly stronger in both of these cases, leading to the overall negative association even though invasibility partially obscures the impacts of invasion at the community level.

\section{Extensions of separating cause from consequence}

There are some interesting extensions of our conceptual framework that suggest invasion may alter community structure at a broader scale under certain circumstances. In cases where invasibility and impacts of an invader are both in the same direction (e.g., low diversity areas are more invaded and invasion leads to species displacement), we would expect to see increased variance in neighborhood diversity across the site. Similarly, in cases where these two processes function antagonistically towards each other (e.g., high diversity areas are more likely to be invaded and there is subsequent species displacement), we would predict an overall decrease in the variance of neighborhood diversity as invasion intensity increases.

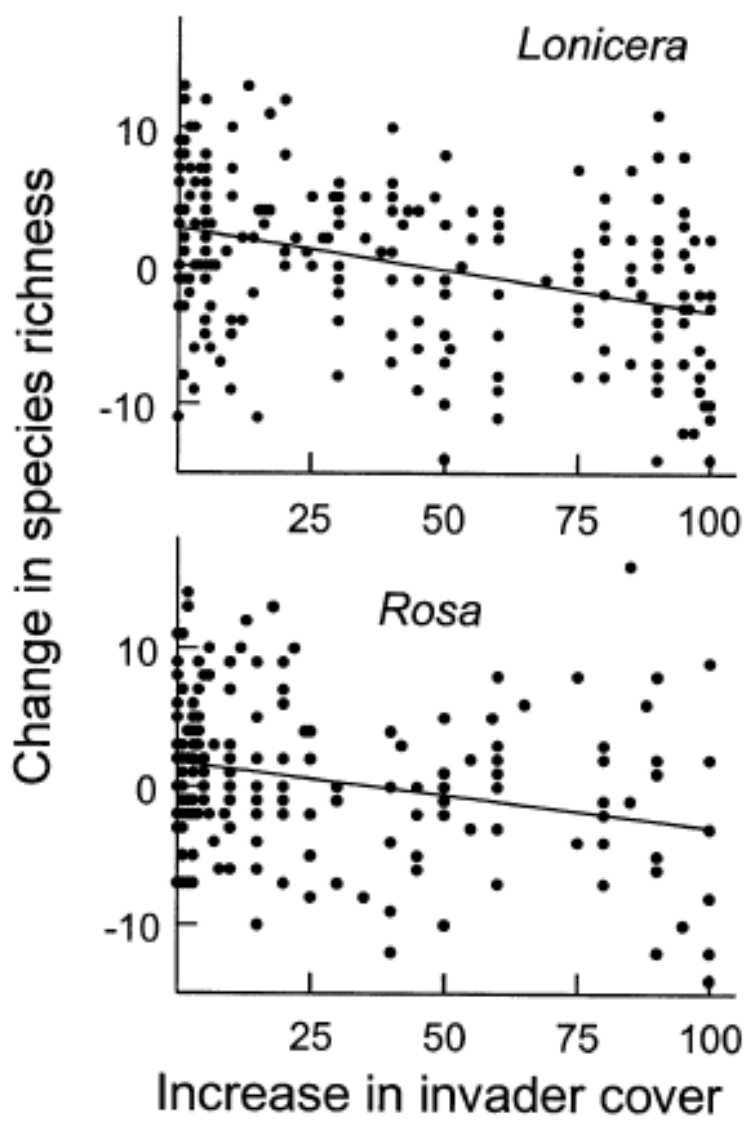

Figure 6. Impacts of invasion on species richness for Lonicera japonica and Rosa multiflora. Regression analysis: Lonicera $-\mathrm{F} 1,218=34.88 ; \mathrm{P}=0.0001 ; \mathrm{R} 2=0.14$; 
Rosa $-\mathrm{F} 1,186=13.53 ; \mathrm{P}=0.0001 ; \mathrm{R} 2=0.07$. Analyses were conducted only on invaded plots only to avoid confounding effects of richness on invasibilty.

Of the three species within the BSS data that show significant species displacement and a positive association between invasion and species richness (Elytrigia repens, Lonicera japonica and Rosa multiflora), only E. repens (a grass) had decreased variance with invasion intensity as predicted. Thus, invaded systems may become more homogeneous during the course of invasion. The variation seen among invaders may represent the intensity of interaction between the invader and resident community and the time scale over which these interactions occur. The two species that did not exhibit a relationship dominate systems for much longer and may generate a response as the invasion proceeds. This relationship should be explored in other systems to see whether it is a common consequence of plant invasions.

The value of long-term monitoring of natural plant communities is clearly evident in the above case studies. The non-experimental nature of this and similar studies actually increases the range and breadth of questions that can be addressed with the resulting data, although direct experimental control has been sacrificed. In unmanipulated systems, the types of relationships and interactions that can be addressed are not limited by experimental protocols designed to separate out a small suite of effects. For this simple reason, a study began to document successional dynamics has been very useful in addressing plant invasions and their impacts.

\section{Conclusions}

Invasion ecology has suffered from the artificial separation of invasibility and impact processes in understanding the relationship between diversity and plant invasion. By studying these independently functioning stages of invasion in concert, we can gain great insight into the biological causes and consequences of invasions, and develop crucial information for the generation of adequate management strategies. Our conceptual framework provides a structure to synthesize the current body of research, suggests research needed to fill the gaps in understanding and to organize results from future research. The framework is a powerful tool to guide ecological understanding of the relationship between invasion and diversity across systems, species, and scales.

The case studies discussed here clearly show how both the cause and consequence of diversity may operate simultaneously within an invasion to generate the community associations often noted in static studies. Currently, it is not possible to make generalizations about which mechanism is the most important because of the extreme lack of information for most plant invasions. To understand the nature of the relationship between diversity and invasion, both of these processes must be assessed to determine their relative contribution. 


\section{Acknowledgments}

Previous versions of this manuscript benefited from comments by SN Handel, JS Johns, STA Pickett, S Ruhren, BE Wachholder and KA Yurkonis. This material is based upon work supported by the following organizations: Council on Faculty Research, Eastern Illinois University; CSREES, US Department of Agriculture, under Agreement No. 99-35315-7695; and the National Science Foundation under award DEB-0424605.

\section{References}

1 Mooney HA, Hamburg SP, Drake JA (1986) The invasion of plants and animals into California. In: HA Mooney (ed.): Ecology of biological invasions of North America and Hawaii. Springer- Verlag, New York, 250-272

2 Robinson GR, Yurlina ME, Handel SN (1994) A century of change in the Staten Island flora: Ecological correlates of species losses and invasions. Bull Torrey Bot Club 121: 119-129

3 Knops JMH, Griffin JR, Royalty AC (1995) Introduced and native plants of the Hastings Reservation, central coastal California: a comparison. Biol Conserv 71: 115-123

4 Stadler J, Trefflich A, Klotz S, Brandl R (2000) Exotic plant species invade diversity hot spots: the alien flora of northwestern Kenya. Ecography 23: 169-176

5 Parker IM, Simberloff D, Lonsdale WM, Goodell K, Wonham M, Kareiva PM, Williamson MH, Von Holle B, Moyle PB, Byers JE et al. (1999) Impact: toward a framework for understanding the ecological effects of invaders. Biol Inv 1: 3-19

6 Woods KD (1997) Community response to plant invasion. In: JO Luken (ed.): Assessment and management of plant invasions. Springer, New York, 56-68

7 Alvarez ME, Cushman JH (2002) Community-level consequences of a plant invasion: effects on three habitats in coastal California. Ecol App 12: 1434-1444

8 Byers JE, Reichard S, Randall JM, Parker IM, Smith CS, Lonsdale WM, Atkinson IAE, Seastedt TR, Williamson M, Chornesky E et al. (2002) Directing research to reduce the impacts of nonindigenous species. Cons Biol 16: 630-640

9 Elton CS (1958) The ecology of invasions by animals and plants. Methuen, London, UK

10 Tilman D (1997) Community invasibility, recruitment limitation, and grassland biodiversity. Ecology 78: 81-92 
11 Crawley MJ, Brown SL, Heard MS, Edwards GR (1999) Invasion resistance in experimental grassland communities: species richness or species identity? Ecol Lett 2: $140-148$

12 Knops JMH, Tilman D, Haddad NM, Naeem S, Mitchell CE, Haarstad J, Ritchie ME, Howe KM, Reich PB, Siemann E et al. (1999) Effects of plant species richness on invasion dynamics, disease outbreaks, insect abundances and diversity. Ecol Lett 2: 286-293

13 Hager HA, McCoy KD (1998) The implications of accepting untested hypotheses: a review of the effects of purple loosestrife (Lythrum salicaria) in North America. Biodiv Conser 7: 1069-1079

14 Stein BA, Flack SR (1996) America's least wanted: alien species invasions of U.S. ecosystems. The Nature Conservancy, Arlington, VA

15 Pickett STA, Collins SL, Armesto JJ (1987) Models, mechanisms, and pathways of succession. Bot Rev 53: 335-371

16 Case TJ (1990) Invasion resistance arises in strongly interacting species-rich model competition communities. Proc Natl Acad Sci 87: 9610-9614

17 McGrady-Steed J, Harris PM, Morin PJ (1997) Biodiversity regulates ecosystem predictability. Nature 390: 162-165

18 Pacala SW, Silander JA (1985) Neighborhood models of plant population dynamics. I. Single-species models of annuals. Am Nat 125: 385-411

19 Levine JM (2000) Species diversity and biological invasions: relating local processes to community pattern. Science 288: 852-854

20 Musil CF (1993) Effect of invasive Australian acacias on the regeneration, growth and nutrient chemistry of South African lowland fynbos. J Appl Ecol 30: 361-372

21 Kwiatkowska AJ, Spalik K, Michalak E, Palin'ska A, Panufnik D (1997) Influence of the size and density of Carpinus betulus on the spatial distribution and rate of deletion of forest-floor species in thermophilous oak forest. Plant Ecol 129: 1-10

22 Yurkonis KA, Meiners SJ (2004) Invasion impacts species turnover in a successional system. Ecol Lett 7: 764-769

23 Bruno JF, Stachowicz JJ, Bertness MD (2003) Inclusion of facilitation into ecological theory. Trends Ecol Evol 18: 119-125

24 Heisey RM (1996) Identification of an allelopathic compound from Ailanthus altissima (Simaroubaceae) and characterization of its herbicidal activity. Am J Bot 
83: $192-200$

25 McCarthy BC, Hanson SL (1998) An assessment of the allelopathic potential of the invasive weed

Alliaria petiolata (Brassicaceae). Castanea 63: 68-73

26 Callaway RM, Aschehoug ET (2000) Invasive plants versus their new and old neighbors: a mechanism for exotic invasion. Science 290: 521-523

27 Callaway RM (1995) Positive interactions among plants. Bot Rev 61: 306-349

28 Walker LR, Smith SD (1997) Impacts of invasive plants on community and ecosystem properties. In: JO Luken (ed.): Assessment and management of plant invasions. Springer, New York, 69-86

29 Ehrenfeld JG (2003) Effects of exotic plant invasions on soil nutrient cycling processes. Ecosyst 6: 503-523

30 Bever JD (2003) Soil community feedback and the coexistence of competitors: conceptual frameworks and empirical tests. New Phytol 157: 465-473

31 Planty-Tabacchi AM, Tabacchi E, Naiman RJ, Deferrari C, Décamps H (1996) Invasibility of species-rich communities in riparian zones. Cons Biol 10: 598-607

32 Stohlgren TJ, Bull KA, Otsuki Y, Villa CA, Lee M (1998) Riparian zones as havens for exotic plant species in the central grasslands. Plant Ecol 138: 113-125

33 Stohlgren TJ, Binkley D, Chong GW, Kalkhan MA, Schell LD, Bull KA, Otsuki Y, Newman G, Bashkin M, Son Y (1999) Exotic plant species invade hot spots of native plant diversity. Ecol Monogr 69: 25-46

34 Lonsdale WM (1999) Global patterns of plant invasions and the concept of invasibility. Ecology 80: 1522-1536

35 Brown RL, Peet RK (2003) Diversity and invasibility of southern Appalachian plant communities. Ecology 84: 32-39

36 Rosenzweig ML, Abramsky Z (1993) How are diversity and productivity related? In: RE Ricklefs (ed.): Species diversity in ecological communities. University of Chicago Press, Chicago, 52-65

37 Tilman D, Pacala S (1993) The maintenance of species richness in plant communities. In: RE Ricklefs (ed.): Species diversity in ecological communities. University of Chicago Press, Chicago, 13-25

38 Brown JH, Lomolino MV (1998) Biogeography. Sinauer Associates, Inc., 
Sunderland

39 Levine JM, D'Antonio CM (1999) Elton revisited: a review of evidence linking diversity and invasibility. Oikos 87: 15-26

40 Thompson K, Hodgson JG, Rich TCG (1995) Native and alien invasive plants: more of the same? Ecography 18: 390-402

41 Fox MD, Fox BJ (1986) The susceptibility of natural communities to invasion. In: RH Groves (ed.): Ecology of biological invasions. Cambridge University Press, Cambridge, UK, 57-66

42 Crawley MJ (1987) What makes a community invasible? In: AJ Gray (ed.): Colonization, succession and stability. Blackwell Scientific Publications, Oxford, UK, 429-453

43 Rejmánek M (1989) Invasibility of plant communities. In: JA Drake (ed.): Biological invasions: a global perspective. John Wiley and Sons, Chichester, UK, 369388

44 Rejmánek M (1999) Invasive plant species and invasible ecosystems. In: OY Sandlund (ed.): Invasive species and biodiversity management. Kluwer Academic Publishers, Dordrecht, The Netherlands, 79-102

45 Fargione J, Brown CS, Tilman D (2003) Community assembly and invasion: An experimental test of neutral versus niche processes. Proc Natl Acad Sci 100: 89168920

46 Hobbs RJ (1989) The nature and effects of disturbance relative to invasions. In: JA Drake (ed.): Biological invasions: a global perspective. John Wiley and Sons Ltd., Chichester, UK, 389-405

47 Burke MJW, Grime JP (1996) An experimental study of plant community invasibility. Ecology 77: 776-790

48 Davis MA, Grime P, Thompson K (2000) Fluctuating resources in plant communities: a general theory of invasibility. J Ecol 88: 528-534

49 Harrison S (1999) Native and alien species diversity at the local and regional scales in a grazed California grassland. Oecologia 121: 99-106

50 Grime JP (2001) Plant strategies, vegetation processes, and ecosystem properties. John Wiley and Sons, Chichester, UK

51 Robinson GR, Quinn JF, Stanton ML (1995) Invasibility of experimental habitat islands in a California winter annual grassland. Ecology 76: 786-794 
52 Prieur-Richard AH, Lavorel S, Grigulis K, Dos Santos A (2000) Plant community diversity and invasibility by exotics: invasion of Mediterranean old fields by Conyza bonariensis and Conyza canadensis. Ecol Lett 3: 412-422

53 Huston MA (1997) Hidden treatments in ecological experiments: re-evaluating the ecosystem function of biodiversity. Oecologia 110: 449-460

54 Stohlgren TJ, Otsuki Y, Villa CA, Lee M, Belnap J (2001) Patterns of plant invasions: a case example in native species hotspots and rare habitats. Biol Inv 3: $37-50$

55 Meiners SJ, Cadenasso ML, Pickett STA (2004) Beyond biodiversity: individualistic controls of invasion in a self-assembled community. Ecol Lett 7: 121126

56 Palmer MW, Maurer TA (1997) Does diversity beget diversity? A case study of crops and weeds. J Veg Sci 8: 235-240

57 Tilman D (1993) Species richness of experimental productivity gradients: how important is colonization limitation? Ecology 74: 2179-2191

58 Naeem S, Knops JMH, Tilman D, Howe KM, Kennedy T, Gale S (2000) Plant diversity increases resistance to invasion in the absence of covarying extrinsic factors. Oikos 91: 97-108

59 Kennedy TA, Naeem S, Howe KM, Knops JMH, Tilman D, Reich P (2002)

Biodiversity as a barrier

to ecological invasion. Nature 417: 636-638

60 Clark JS, Carpenter SR, Barber M, Collins S, Dobson A, Foley JA, Lodge DM, Pascual M, Pielke R, Pizer W et al. (2001) Ecological forecasts: an emerging imperative. Science 293: 657-660

61 Richardson DM, Macdonald IAW, Forsyth GG (1989) Reductions in plant species richness under stands of alien trees and shrubs in the Fynbos biome. S Afr For J 149: $1-8$

62 Wyckoff PH, Webb SL (1996) Understory influence of the invasive Norway maple (Acer platanoides). Bull Torrey Bot Club 123: 197-205

63 Collier MH, Vankat JL (2002) Diminished plant richness and abundance below Lonicera maackii, an invasive shrub. Am Midl Nat 147: 60-71

64 Christian JM, Wilson SD (1999) Long-term ecosystem impacts of an introduced grass in the northern Great Plains. Ecology 80: 2397-2407 
65 Wiser SK, Allen RB, Clinton PW, Platt KH (1998) Community structure and forest invasion by an exotic herb over 23 years. Ecology 79: 2071-2081

66 Smith MD, Knapp AK (1999) Exotic plant species in a C4-Dominated grassland: invasibility, disturbance, and community structure. Oecologia 120: 605-612

67 Treberg MA, Husband BC (1999) Relationship between the abundance of Lythrum salicaria (purple loosestrife) and plant species richness along the Bar River, Canada. Wetlands 19: 118-125

68 Hager HA, Vinebrooke RD (2004) Positive relationships between invasive purple loosestrife (Lythrum salicaria) and plant species diversity and abundance in Minnesota wetlands. Can J Bot 82: 763-773

69 Woods KD (1993) Effects of invasion by Lonicera tartarica L. on herbs and tree seedlings in four New England forests. Am Midl Nat 130: 62-74

70 Meiners SJ, Pickett STA (1999) Changes in community and population responses across a forestfield gradient. Ecography 22: 261-267

71 Anderson MG (1995) Interactions between Lythrum salicaria and native organisms: a critical review. Environ Manage 19: 225-231

72 Meiners SJ, Pickett STA, Cadenasso ML (2001) Effects of plant invasions on the species richness of abandoned agricultural land. Ecography 24: 633-644

73 D'Antonio CM, Mahall BE (1991) Root profiles and competition between the invasive exotic perennial, Carpobrotus edulis, and two native shrub species in California coastal scrub. Am J Bot 78: 885-894

74 Dillenburgh LR, Whigham DF, Teramura AH, Forseth IN (1993) Effects of vine competition on availability of light, water, and nitrogen to a tree host (Liquidambar styraciflua). Am J Bot 80: 244-252

75 Marler MJ, Zabinski CA, Callaway RM (1999) Mycorrhizae indirectly enhance competitive effects of an invasive forb on a native bunchgrass. Ecology 80: 11801186

76 D’Antonio CM, Flint HR, Mack M, Hitchcock D,Vitousek PM (1998) The response of native species to removal of invasive exotic grasses in a seasonally dry Hawaiian woodland. J Veg Sci 9: 699-712

77 Miller KE, Gorchov DL (2004) The invasive shrub, Lonicera maackii, reduces growth and fecundity of perennial forest herbs. Oecologia 139: 359-375 
78 Gould AMA, Gorchov DL (2000) Effects of the exotic invasive shrub Lonicera mackii on the survival and fecundity of three species of native annuals. Am Midl Nat 144: $36-50$

79 Kwiatkowska AJ, Wyszomirski T (1990) Species deletion in Potentillo albaeQuercetum phytocoenoses reversed by the removal of Carpinus betulus. Vegetatio 87: $115-126$

80 McCarthy BC (1997) Response of a forest understory community to experimental removal of an invasive nonindigenous plant (Alliaria petiolata, Brassicaceae). In: J0 Luken (ed.): Assessment and management of plant invasions. Springer, New York, $117-130$

81 Webb SL, Pendergast IV TH, Dwyer ME (2001) Response of native and exotic maple seedling banks to removal of the exotic, invasive Norway maple (Acer platanoides). J Torrey Bot Soc 128: 141-149

82 Pickart AJ, Miller LM, Duebendorfer TE (1998) Yellow bush lupine invasion in Northern California coastal dunes I. Ecological impacts and manual restoration techniques. Restor Ecol 6: 59-68

83 Luken JO, Kuddes LM, Tholemeier TC (1997) Response of understory species to gap formation and soil disturbance in Lonicera maackii thickets. Rest Ecol 5: 229235

84 Luken JO, Thieret JW (1996) Amur honeysuckle, its fall from grace. BioScience 46: $18-24$

85 Luken J0, Goessling N (1995) Seedling distribution and potential persistence of the exotic shrub Lonicera maackii in fragmented forests. Am Midl Nat 133: 124-130

86 Hutchinson TF, Vankat JL (1998) Landscape structure and spread of the exotic shrub Lonicera maackii (Amur honeysuckle) in southwestern Ohio forests. Am Midl Nat 139: 383-390

87 Hutchinson TF, Vankat JL (1997) Invasibility and effects of Amur honeysuckle in southwestern Ohio forests. Cons Biol 11: 1117-1124

88 Gorchov DL, Trisel DE (2003) Competitive effects of the invasive shrub, Lonicera maackii (Rupr.) Herder (Caprifoliaceae), on the growth and survival of native tree seedlings. Plant Ecol 166: 13-24

89 Hartman KM, McCarthy BC (2004) Restoration of a forest understory after the removal of an invasive shrub, Amur honeysuckle (Lonicera maackii). Rest Ecol 12: 154-165 
90 Turnbull LA, Crawley MJ, Rees M (2000) Are plant populations seed-limited? A review of seed sowing experiments. Oikos 88: 225-238

91 Zobel M, Otsus M, Liira J, Moora M, Möls T (2000) Is small-scale species richness limited by seed availability or microsite availability? Ecology 81: 3274-3282

92 Bazzaz FA (1996) Plants in changing environments. Cambridge University Press, Cambridge, UK

93 Rejmánek M, Richardson DM (1996) What attributes make some plant species more invasive. Ecology 77: 1655-1661

94 Meiners SJ, Pickett STA, Cadenasso ML (2002) Exotic plant invasions over 40 years of old field succession: community patterns and associations. Ecography 25: 215-223

95 Lodge DM (1993) Biological invasion: lessons for ecology. Trends Ecol Evol 8: 133-137

96 Blossey B (1999) Before, during and after: the need for long-term monitoring in invasive species management. Biol Inv 1: 301-311

97 Fike J, Niering WA (1999) Four decades of old field vegetation development and the role of Celastrus orbiculatus in the northeastern United States. J Veg Sci 10: 483492

98 Kwiatkowska AJ, Wyszomirski T (1990) Species deletion in Potentillo albaeQuercetum phytocoenoses reversed by the removal of Carpinus betulus. Vegetatio 87: $115-126$

99 Kwiatkowska AJ, Spalik K, Michalak E, Palin'ska A, Panufnik D (1997) Influence of the size and density of Carpinus betulus on the spatial distribution and rate of deletion of forest-floor species in thermophilous oak forest. Plant Ecol 129: 1-10 100 Pickett STA (1982) Population patterns through twenty years of oldfield succession. Vegetatio 49: 45-59

101 Schweitzer JA, Larson KC (1999) Greater morphological plasticity of exotic honeysuckle species may make them better invaders than native species. J Torrey Bot Soc 126: 15-23

102 Amrine JW, Stasny TA (1993) Biocontrol of multiflora rose. In: BN McNight (ed.): Biological pollution: the control and impact of invasive exotic species. Indiana Academy of Science, Indianapolis, 9-21

103 Bartha S, Meiners SJ, Pickett STA, Cadenasso ML 2003) Plant colonization windows in a mesic old field succession. App Veg Sci 6: 205-212 